\title{
Wide Band Series Switch Fabricated Using Metal As Sacrificial layer
}

\author{
Yongming Cai and Linda P.B. Katehi \\ Radiation Laboratory, Department of Electrical Engineering and Computer Science \\ University of Michigan, Ann Arbor, MI 48109,USA \\ ycai@eecs.umich.edu, katehi@engin.umich.edu
}

\begin{abstract}
Series switches with metal-to-metal contact have been fabricated to operate from dc to $40 \mathrm{GHz}$. The insertion loss has been measured to be less than $0.4 \mathrm{~dB}$ at $5 \mathrm{GHz}$ and $0.8 \mathrm{~dB}$ at $40 \mathrm{GHz}$ when switch is on and the isolation ranges from 38 $\mathrm{dB}$ at $2 \mathrm{GHz}$ to $15 \mathrm{~dB}$ at $40 \mathrm{GHz}$ when the switch is off. The results agree well with simulation by Zeland IE3D. Cantilever beam is used as the mechanical structure and CPW line works as the transmission line. The cantilever is made of $\mathrm{SiO}_{2}$ and $\mathrm{Al}$ is used as the sacrificial layer.
\end{abstract}

\section{INTRODUCTION}

MEMS switches have been developed for low loss RF control circuits [1-3]. The ultimate goal of this research is to build wide band, high isolation and low- loss single pole multi-through switches for deep space telecommunications. The current work is focused on designing, modeling, fabricating and testing a SPST switch using cantilever beam as the mechanical structure and coplanar waveguide (CPW) as the transmission line. The switches (Fig.1) have been fabricated with $\mathrm{SiO}_{2}$ as the beam material and $\mathrm{Al}$ as the sacrificial layer.

Fig. 1 Series switch fabricated with cantilever beam and $\mathrm{Au}-\mathrm{Au}$ contact.

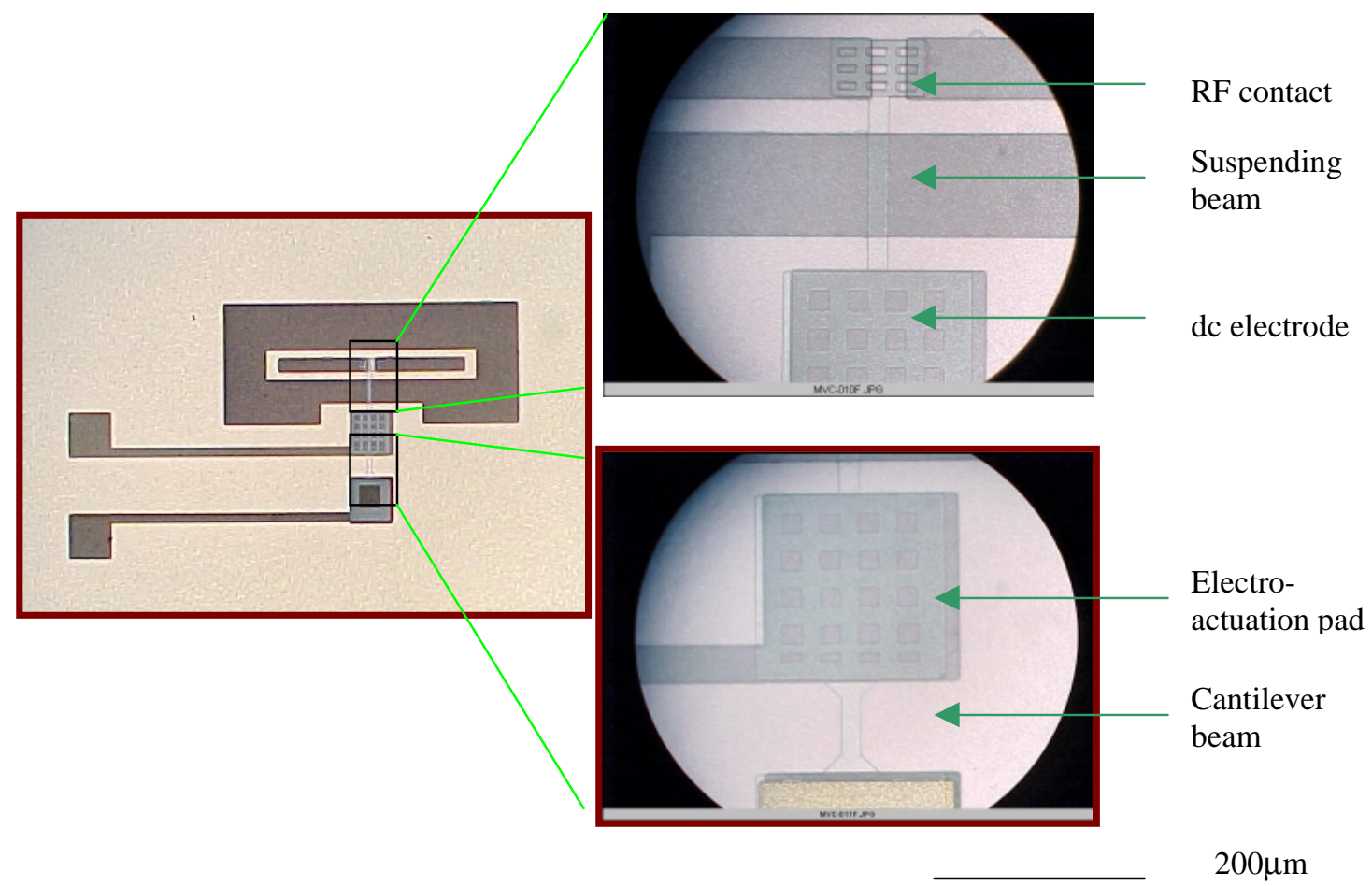




\section{II . DESIGN AND SIMULATION}

The cantilever beam is made of $\mathrm{SiO}_{2}$ and is $200 \mu \mathrm{m}$ in length, $20 \mu \mathrm{m}$ in width and $1 \mu \mathrm{m}$ in thickness. The electrostatic actuation pad is made of $1 \mu \mathrm{m} \mathrm{Au}$ and has lateral dimension of $200 \mu \mathrm{m}$ x $200 \mu \mathrm{m}$. When the switch is off, the gap between the switch contact underneath the silicon dioxide cantilever beam and the top of the center conductor of the CPW line is $2 \mu \mathrm{m}$. The $\mathrm{Au} \mathrm{CPW}$ transmission line is $2 \mu \mathrm{m}$ thick and the Au contact is $1 \mu \mathrm{m}$ thick. The CPW line has

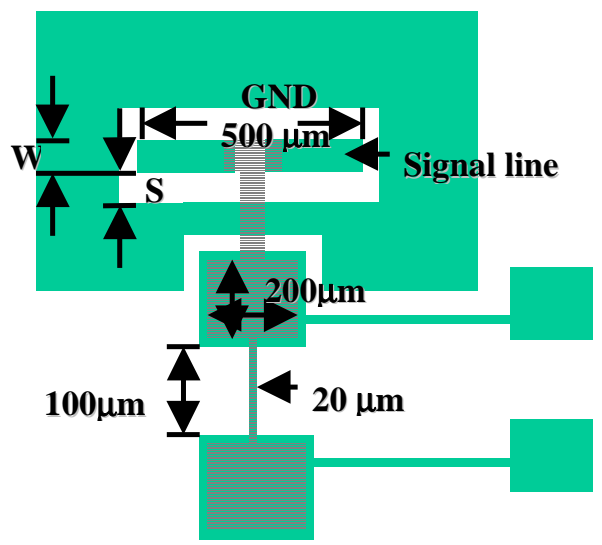

Fig 2. Top view of the switch.

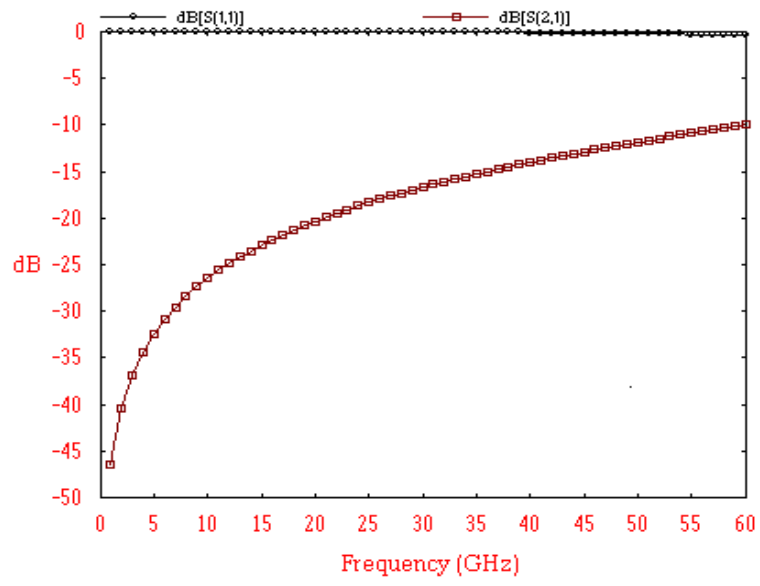

Fig 4. Simulated insertion loss and isolation when switch is off . dimensions of $(\mathrm{S} / \mathrm{W} / \mathrm{S}=40 / 60 / 40 \mu \mathrm{m})$ chosen for the $50 \Omega$ transmission line at $30 \mathrm{GHz}$ (see Fig. 2 and 3). The width of finite ground is $200 \mu \mathrm{m}$. The switch has been implemented on a high resistivity silicon substrate and has been designed to actuate at $20 \mathrm{~V}$. The Zeland IE3D simulated results are shown in Fig 4. and Fig. 5. Clearly, this type of switch will have isolation of $40 \mathrm{~dB}$ (at dc) to $15 \mathrm{~dB}$ (at $40 \mathrm{GHz}$ ) when is off and $0 \mathrm{~dB}$ insertion loss when is in on state since the simulation includes zero Ohmic losses when the switch is on .

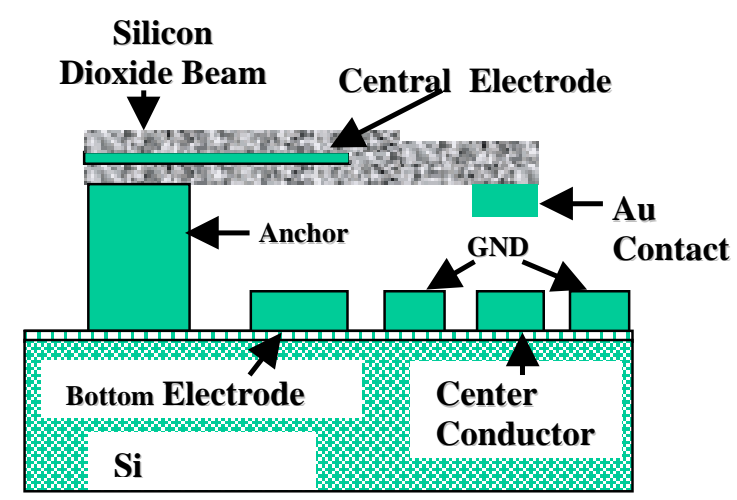

Fig. 3 Side view of the switch.

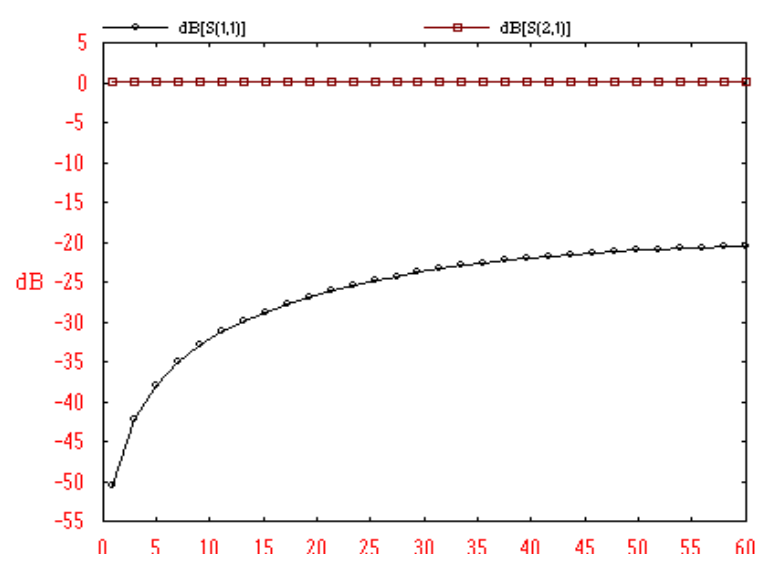

Fig 5. Simulated insertion loss and isolation when switch is on 


\section{FABRICATION}

The fabrication steps are: 1) sputtering $2 \bullet \mathrm{m}$ $\mathrm{Al} 2)$ lithography and etch of $\mathrm{Al}$ to make the mold for Au evaporation; 3)evaporation of $2 \cdot \mathrm{m} \mathrm{Au}$ and lift-off to form the circuit; 4) lithography and evaporation of another $2 \cdot \mathrm{m} \mathrm{Au}$ and lift-off to deposit another $2 \cdot \mathrm{m}$ onto the anchor portion of the circuit; 5) sputtering of another $2 \cdot \mathrm{m} \mathrm{Al}$ as sacrificial layer,6) evaporation of $1 \cdot \mathrm{m} \mathrm{Au}$ and lift-off to form the contact; 7) deposition of 1 - $\mathrm{m}$ silicon dioxide; 8) RIE etch of the silicon dioxide to form the beam and open a via on the anchor part. This via provides contact of the center electrode to the anchor; 10) evaporation of 2000 - $\mathrm{Au}$ and lift-off to make the center electrode. 11) etch of the sacrificial $\mathrm{Al}$ and releasing of the switch using critical point drying.

\section{MEASUREMENT}

The measurements are based on an on-wafer TRL calibration. From dc to $40 \mathrm{GHz}$, the isolation ranges from $38 \mathrm{~dB}$ at $2 \mathrm{GHz}$ to $15 \mathrm{~dB}$ at $40 \mathrm{GHz}$ when the switch in off state (Fig. 6). The off-state result agrees very well to the simulated result indicating that the structure has been fabricated according to the design and was released successfully. This process is simple and easy to implement. Since no polyamide or photoresist is needed as sacrificial layer, the thickness is easy to control and can sustain high temperature process. Metal is evaporated as sacrificial layer as well as circuit; hence, it is easy to control the vertical and lateral dimension.

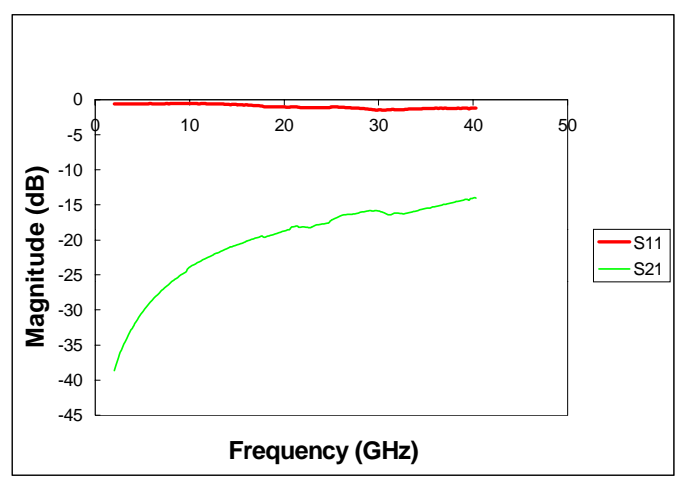

Fig.6 Measured Insertion loss and isolation from $2 \mathrm{GHz}$ to $40 \mathrm{GHz}$ when switch is off
The insertion loss has been measured to be 0.4 $\mathrm{dB}$ at $5 \mathrm{GHz}$ and $0.8 \mathrm{~dB}$ at $40 \mathrm{GHz}$ when switch is on (Fig. 7). We think this is due to the large holes on the RF contact which is designed to help to reduce dampening and assist the etch of sacrificial layer. The RF has been forced into narrow current and loss is increased; otherwise, the loss is expected to be $0.2 \mathrm{~dB}$ around $20 \mathrm{GHz}$ if no holes on the RF contact. We will modify the design and the latest results will be presented at the conference.

\section{REFERENCES}

[1] Elliott R. Brown, "RF-MEMS Switches for Reconfigurable Integrated Circuits", IEEE Trans. Microwave Theory Tech., Vol. 46, No.11, Nov 1998, pp. 1868-1880.

[2]J.J.Yao and M.F.Chang, "A surface micromachined miniature switch for telecommunications with signal frequencies from

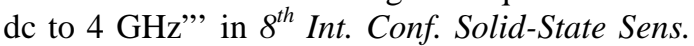
Actuators, Stockholm, Sweden, June 25, 1995, pp. 384-387.

[3] S.Pacheco, C.T.Nguyen, and L. P.B. Katehi, "Micromechanical electrostatic k-band switches", in the IEEE MTT-S Int. Microwave Symp. Dig., Baltimore, MD, June 1998, pp. 1569-1572.

\section{ACKNOWLEDGEMENT}

The work was partially supported by JPL/CISM/SOAC and by DARPA Recap Program. The authors would like to thank Sergio Pacheco and Dimitrios Peroulis for their help.

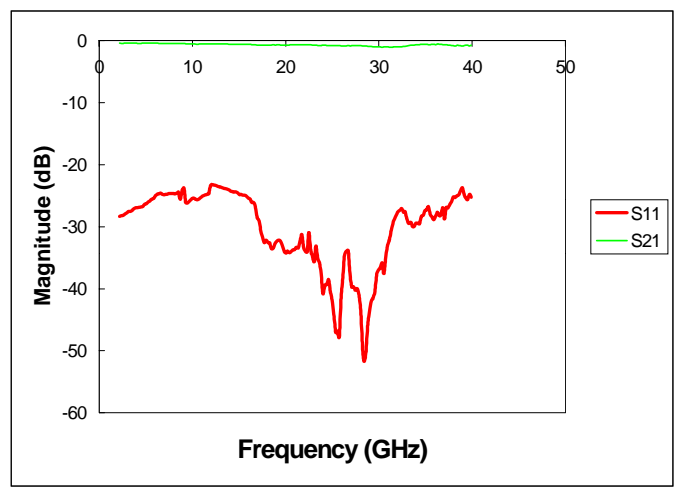

Fig.7 Measured Insertion loss and isolation from $2 \mathrm{GHz}$ to $40 \mathrm{GHz}$ when switch is on 